Macedonian Pharmaceutical Bulletin, 66 (Suppl 1) 35 - 36 (2020)

Online ISSN $1857-8969$

UDC: $616.24-002.28-083.2$

DOI: 10.33320/maced.pharm.bull.2020.66.03.017

Short communication

\title{
Nutrition in COPD patients - case study
}

\author{
Elena Karabeleski*, Lidija Petrushevska-Tozi, Bojana Janeku, Suzana Atanasovikj, \\ Dafina Boshkoska, Menka Andreska, Dragana Mladenovska, Tanja Petreska Ivanovska, \\ Aleksandra Kapedanovska Nestorovska, Kristina Mladenovska
}

Faculty of Pharmacy, Ss. Cyril and Methodius University, Mother Theresa No. 47, 1000 Skopje, N. Macedonia

\section{Introduction}

Chronic obstructive pulmonary disease (COPD) is a progressive disease that limits airflow through either inflammation of the lining of the bronchial tubes (bronchitis) or destruction of alveoli (emphysema). COPD according to statistics from the WHO is the fourth leading cause of death overall in the face of decades and expected to be increased.

Medical treatment for individuals with COPD involves lifestyle changes, including smoking cessation, avoiding smoke and other air pollutants, exercising as tolerated and good nutrition. As COPD progresses, symptoms such as shortness of breath, taste alterations due to dry mouth, fatigue, early feelings of fullness, etc. can contribute to decreased food intake. Disease-related malnutrition is a common problem in individuals with COPD, with between $30 \%$ and $60 \%$ of inpatients and $10 \%$ and $45 \%$ of outpatients said to be at risk (Collins et al., 2013). A prolonged decrease in food intake can lead to significant weight loss and malnutrition. For better clinical outcome and patients' quality of life, the nutrition care plan should be provided by dietitian.

The aim of this paper is to present an approach of nutritional therapy in a patient with COPD and to emphasize the role of the certified nutrition in nutrition assessment, diagnosis and intervention in COPD patients.

\section{Case presentation}

In a 62-year-old female patient with a medical history of bronchitis and upper respiratory infections, COPD was diagnosed five years ago. The patient was admitted to the hospital complaining of severe dyspnea and fatigue, showing signs of cyanosis, and using accessory muscles for expiration. PEFR of $190 \mathrm{~L} / \mathrm{min}$ and pulse of 100/min were determined. The patient was not a smoker (she quit smoking 5 years ago). She was additionally diagnosed with acute exacerbation of COPD, secondary to pneumonia. The patient indicated that her appetite was poor and the food did not taste good. Her highest adult weight was $63-68 \mathrm{~kg}$ (about 5 years ago), and $54 \mathrm{~kg}$ at the time of hospitalization $\left(\right.$ BMI $\left.27.6 \mathrm{~kg} / \mathrm{m}^{2}\right)$. She complained that her dentures were fitting very loosely. She had $1+$ bilateral pitting edema, decreased breathing sounds and prolonged expiration with wheezing and she used accessory muscles at rest. Laboratory analysis pointed to albumin $3.4 \mathrm{~g} / \mathrm{dL}, \mathrm{pH} 7.29, \mathrm{PaCO}_{2} 50.9 \mathrm{mmHg}$, $\mathrm{PaO}_{2} 77.7 \mathrm{mmHg}, \mathrm{O}_{2} \mathrm{Sat} 92 \%, \mathrm{HCO}_{3} 29.6 \mathrm{mEq} / \mathrm{L}$. Her usual dietary intake included: coffee, juice and dry cereal, with a small amount of milk in the morning and one other larger meal during the day, usually at lunch (consisted of meat, vegetables, rice, potatoes or pasta). She admitted that she was eating only small portions. At night she often had a bowl of soup. She used to drink cola throughout the day (usually $1 \mathrm{~L}$ ). Her pharmacotherapy was consisted of inhaler salbutamol $2.5 \mathrm{mg}$ and ipratropium bromide $500 \mathrm{mcg}$ and i.v cefuroxime $750 \mathrm{mg}$, each three

*ekarabeleski@gmail.com 
times daily, oral aminophylline retard $225 \mathrm{mg}$ two times daily and oral prednisolone in the morning in dosage regimen adjusted by scheme until achieving the desired clinical response.

\section{Discussion}

For nutrition assessment, patient's biochemical data and anthropometrical measurements were analyzed, while for nutrition diagnosis to be established, problem, etiology and signs/symptoms (PES I) of the patient, inadequate calorie intake (due to loss of appetite, taste deterioration and problems with dental prostheses) (PES II) as well as unintentional weight loss due to COPD (reduction of $10 \mathrm{~kg}$ compared to normal weight) (PES III) were considered. By MUST screening tool, score $\geq 2$ was determined and high risk for malnutrition, even with BMI $27.6 \mathrm{~kg} / \mathrm{m}^{2}$.

Nutrition intervention included recommendations for intake of small frequent meals (5-6 meals per day), dense in nutrient content, with sufficient calories for weight gain, including meals that require little preparation (e.g. liquid nutritional supplements), resting before meals and taking daily dose of multivitamins (vitamin C, D, E). The patient was advised to replace the use of carbonated soft drink with water and naturally squeezed juice. Consuming juice during a meal was not recommended, avoiding was suggested, as the patient was quickly sated. The benefits of fruits and vegetable in chronic and acute respiratory conditions were emphasized due to the antioxidants, minerals, vitamins, flavonoids, phytochemicals, and fiber contents. Omega-3 polyunsaturated fatty acids (PUFA) were also included due to their antiinflammatory effect and potential benefit in COPD and also in malnourished patients. Oral nutritional supplements (standard formula $300 \mathrm{kcal}$ ) were also introduced as a replacement for one meal 1-2 times a day. Based on Harris Benedict formula, total daily calorie needs for the patient were calculated, being 1350-1620 kcal (140\% above BMR), or 25-30 $\mathrm{kcal} / \mathrm{kg}$, with $20 \%$ of total intake for protein $(1.2-1.7$ $\mathrm{g} / \mathrm{kg}$ ) (Deutz et al., 2014).

The use of glucocorticosteroids in the treatment of COPD has been shown to increase the incidence of osteoporosis. Glucocorticosteroids decrease the intestinal absorption of calcium and increase urinary excretion, resulting in an increase in parathyroid hormone levels and bone resorption. Therefore, measurement of bone mineral density was indicated, including daily intake of calcium 1200 to 1500 $\mathrm{mg} /$ day and $400 \mathrm{IU}$ of vitamin D at least (Bergman and Hawk, 2010). Nutrition monitoring with 24-hour dietary recall method was recommended, including monitoring of the ability to perform every day activities, physical appearance, and appetite, disease progression and also weight change. Weight gain of $2 \mathrm{~kg}$ in period of $>2$ weeks was used as a therapeutic target associated with functional improvements (Collins et. al., 2013).

\section{Conclusion}

Malnutrition is prevalent among patients with COPD and can have serious consequences for both the individual and local health economy. The causes of malnutrition in COPD are multifactorial and include reduced energy intake due to decreased appetite, depression, lower physical activity and dyspnea while eating. To achieve a more effective nutrition intervention, systematic nutrition management, continuous data reporting, and the use of an interdisciplinary team approach (including certified dietitian) are needed.

\section{References}

Bergman, E.A., Hawk, S.N., 2010. Diseases of the respiratory system, second ed., in: Cossio, Y. (Ed.), Nutrition Therapy and Pathophysiology. Cengage Learning, Belmont, pp. 648-681.

Collins, P.F., Elia, M., Stratton, R.J., 2013. Nutritional support and functional capacity in chronic obstructive pulmonary disease: A systematic review and metaanalysis. J. Respirology 18, 616-629.

Deutz, N.E.P., Bauer, J.M., Barazzoni, R., Biolo, G., Boirie, Y., Bosy-Westphal, A., Cederholm, T., CruzJentoft, A., Krznariç, Z., Nair, K.S., Singer, P., Teta, D., Tipton, K., Calder, P.C., 2014. Protein intake and exercise for optimal muscle function with aging: Recommendations from the ESPEN Expert Group. J. Clin. Nutr. 30, 1-8. 